\title{
Artiche XI.
}

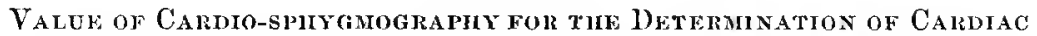
Valvelar Coximions ani of Axburism, Particulariy for Examiners in hife Insurance. By A. B. Ishad, M.D., of Cincinnati, Ohio.

Тне graphic method in diseases of the circulatory apparatus has, within the past few ycars, made such positire additions to onr means of arriving at certain conclusions in regard to valvular affections of the lieart and calibre changes in the principal arterial vessels, that no plysician, who has to deal with such conditions, should content himself to rest in ignorance of the method and its results. It is of particular importance that examiners in life insurance should know what cardio-sphyomography has accomplished, and should be competent to avil thenselves of the advantages which it offers in elearing up doubtful cardiac physical signs. They occupy a position of peculiar responsibility, both toward the company by which they are engaged and toward the genem public. It is their duty to the former to recommend only clean risks, about which there hangs nothing to stand in relation to a future fatal disease. Therefore, in a person presenting with cardiac unumur, they cannot upou physical signs, and objective signs, and applicant's history, predicate a positive opinion that an existing murmur is purely functional without significance as regards the structural integrity of the organ, and it is manifestly obligatory upon them to class the risk as doubtful. In doing this, while the company may be deprived of some good risks, compensation is probably more than cstablished by a preponderance of what might hate proved bad risks. It might scem here that the balance is in farour of the company, and the obligation toward it fulfilled; but the balanee is not in farour of the company, and the obligation is not fulfilled if there exists any possible way of separating the good liom the bad. On the other hand, eluty to the public demands that none who come within the limits of application physically sound, desirinor the bencfits of life insurance, shomld be excluded. If, then, a perfectly healthy applicant is rejected by reason of a sound, pertaining simply to some mechanical factor, standing in no sort of relation to a pathological process, but which appertaining to another individual would be indicative of glave alterations of vital struetures, he suffers an injustice for which the medical examiner is not blameless if there be any way of discriminating as to the nature of the murmur in the one case or the other. The applicant and his assigns are injured in that they are deprived of the benefits which life insurance, in its varions forms, affords, and to which they should be entitled.

It is the object of this paper to present in a plain practical light what assistance cardio-sphygmography lias proved capable of rendering toward the elucidation of the dubious clements in the order of occurrences we liave 
referred to. By the term cardio-sphygmography, of course is meant the simultaneous tracing of the heart and some one of the arteries, one trace above the other, upon the same recciving slide or tablet, together with a time trace below, in scconds or fractions, so that differences in time between the two traces may be easily and accurately computed. The difference in time between the contraction of the ventricles of the heart and the impulse in an artery-or the time difference between two portions of the same artery, or an arterial trunk and one of its branches-forms the basis upon which the dednctions from sphygmographic tracings are principally male. Hence it may bc seen that instruments which we eapable of registering only a single trace, and have no clronographic attuchment, have little clinical or physiological value. To be able to draw correct inferences respecting the double registry in any particular case, we must know what are the normal time differences between the heart and the wrious arterics whicl permit of investigntion. These have been very closely determined by Dr. A. 'T. Keyt, by means of his compound sphygmograph, as follows: with a heart beating at the rate of 722 pulsations per minute.

The average time difference between the contration of the ventricle and the pulsation in the carotid artery is about .0833 of a second $=$ to 7 ? of' a second.

The avernge time differencc between the heart and the temporal artery' in front of the extcrual auditory meatus is about .100 second, or y second.

between the heart and the subclavian artery, above the clavicle, abont .077 second $=$ to $i^{1} 3$ second.

Between the leart and the radial artery about .1538 second $=$ to $\frac{1}{6} \cdot s$ second.

Between the lieart and the femoral artery about . $1428=$ to $\frac{1}{7}$ second.

Between the lieart and the dorsalis pedis artery about $.216=$ to $\frac{1}{5}$ sccoml.

'Tle cardio-carotil time difference is alproximately ont-tenth the duration of the pulsation. Thus, if the pulsc-rate is 60 per minute, the pulsttion is one second long, and the normal time difference would be $\frac{10}{10}$ of a sccond ; if the pulse-rate is 72 , the pulsation las a duration of $\frac{80}{7}=$ to of a second, and the normal time-difference between the heart and curotid artery would be ${ }_{1 \frac{1}{0}}$ of $\frac{5}{6}$, which equals $\frac{1}{12}$ of a second. This ratio of difference to duration of pulsation lolds between 60 and 120 beats per minute, but beyond these limits there is no certainty that it obtains.

The carotid artery is commonly selected in making comparisons of time difference, because it is nearcst the heart of any artery reallily accessible. for observation, and in points involving the integrity of the central organ. or the ascending or transverse portions of the norta, it must necessarily furnish the least eqnivocal splyygmographic data.

Variations in the normal time interval are producel by aneurism, leavy aortic valves, aortic regurgitation, mitral regurgitation, and rigitl arteries. 
1882.] Is н A M, Cardio-Sphygmography in Life Insurance.

INCRFASING TIMF-1NTERVAL.

Alleurism.

Heavy artic valves.

Mitral regurgitation.
DEC1RASING TIME-IXTTERVAL.

Aortic regrnrgitation.

Rigid arteries.

Ixcreasing the Cardo-arterial Time-differexce or Intrrval. Aneurism.-It has been demonstrated by M. Francois Franck ${ }^{1}$ and Dr. Keyt ${ }^{2}$ that aneurism retards the transmission of the artcrial wave between the heart and the vessels beyond the aneurism, which receive theil blood-supply through it. However, according to the clinical observations of Dr. Keyt, ${ }^{3}$ aneurism, to cause pulse delay, must have "frec communications, large cavity, and yielding walls," whilc one with converse characteristics, "narrow orifice or small cavity, or resisting walls, may show 110 abnormal retardation. Deformation of the pulse las no value in the sphygmographic consideration of aneurism, indicating only "arterial obstruction which may originate fion other conditions as well as anenrism."

Fig. 1 supplies the tracings in a case of aneurism of left popliteal artcry: showing the delay typical of the aneurismal condition.

Fig. 1.

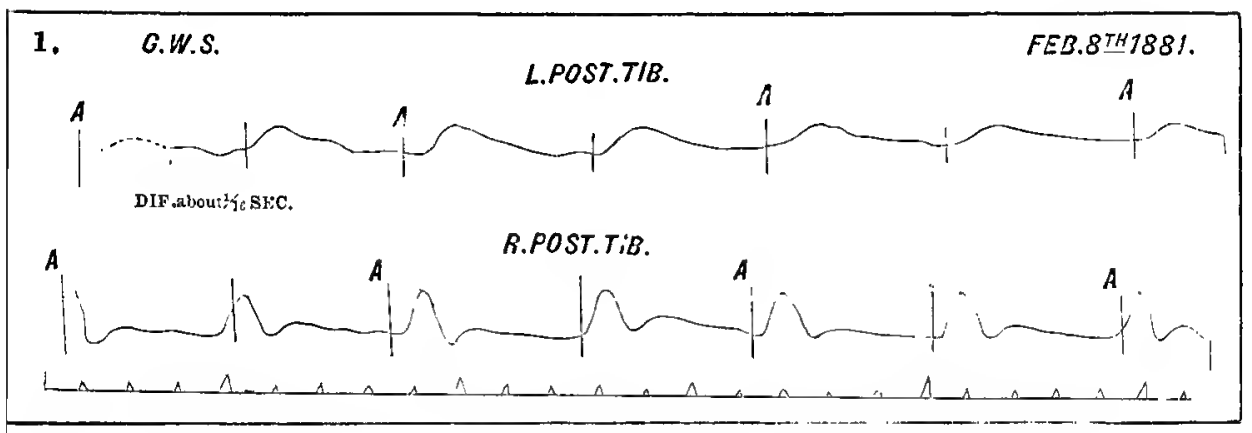

Time-diference between posterior tibials about $\frac{1}{10}$ second. Nornally there should be no difference in time.

Heavy Aortic Valves._-That lieavy aortic valves induce abnormal pulse delay has been slown by Dr. Keyt." The influence of these factors non the time-difference is well shown by the accompanying graphic delineation, Fig. 2, together with the more salient post-mortem fentures of the case from which it was obtained.

I made the post-mortem cxamination, assisted by Drs. Kreyt and Lowry, April 9, 1881. Left rentricle lypertrophied, lelt auricle normal, right auricle and ventricle dilated and hypertioplied; mitral, tricuspid, and pulmonary valve normal. Aortic valves hal deposited upon their upper

1 Journal de l'Anat. de la Physiol., t. xv. (Mars-April, 1879).

- Boston Med. and Surg. Journal, Sept. 30, 1880.

N. Y. Med. Record, Nov. 29, 1879.

- Mei. Record, Julle 4, 1851. 
Fig. 2.

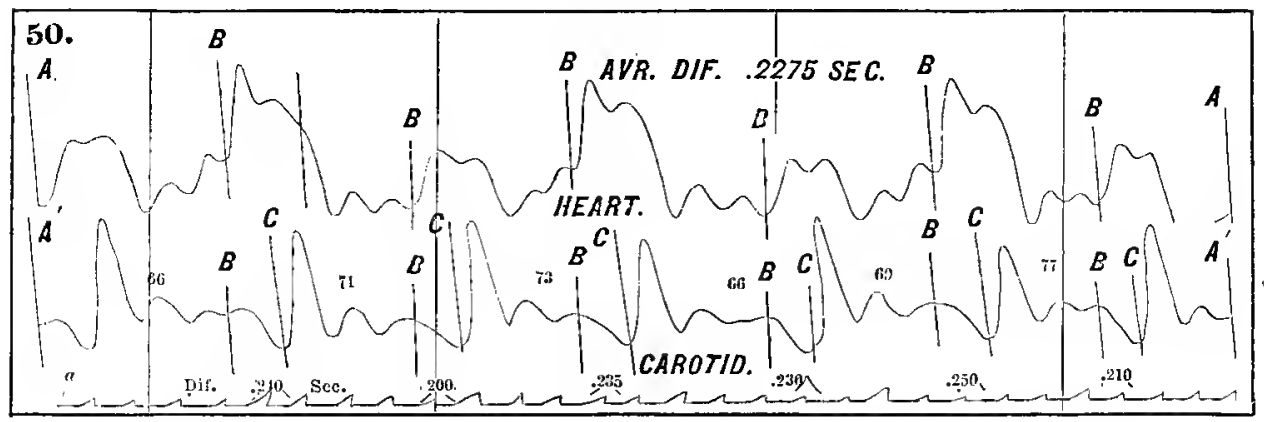

A verage iiue-difference in Fig. $2, .2275$ second $=$ to $\frac{1}{4}$ second. Aormal time-difference $\frac{1}{12}$ second.

surfaces enormons masses of rough ealcareous matter. The overlapping borders of two segments, in nearly half their extent were united, forming a rigid septum, and leaving a triangular space into which fitted the third segment. 'This segment was pliable, and though it contained a calcareous deposit, measuring three-eighths of an iwch in its thickest part, it performed the office of opening and closing the orifice, and did not permit of regureritation. When closed, the segment overlapped by a hithe the rigid border of the opening, but slight pressnre would canse it to sink below the rim, where it remained, as if locked, until commensurate pressure was applied in the opposite direction.

Mitrul Regurgitation. - The cardio-sphygmographic researehes of 'Dr. Keyt ${ }^{1}$ have revealed a notable pulse delay from mitral regurgitation. Fig. 3 is in illustration.

Fig. 8.

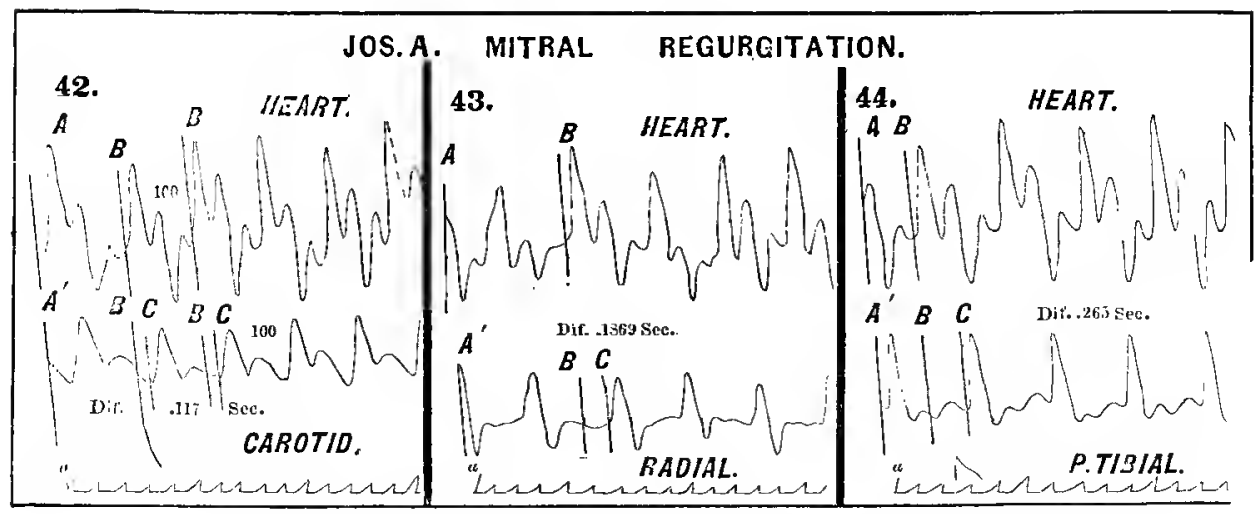

Cardio-carotid time-difference .117 second or between the $\frac{1}{s}$ : 1 nd $\frac{1}{9}$ second. The normal timedifference with pulse at 100 , as in this case, sliould be $\frac{1}{1}$ second.

1 Cin. Lancet and Clinic, March 29, and April 19, 1879, and N. Y. Med. Record, Feb. 14,1880 . 
The post-mortem examination of the subject furnishing tlic above tracingr, as conducted by myself, assisted by Drs. Keyt and Mecum, showed cardiac hypertrophy, normal aortic, tricuspid, and pilmonic valves, while the scgments of the mitral valves were thick and leatlery, witl a thick layer of firm vegetations upon the amricular surface of the larger segment; the auriculo-ventricular orifice guarded by this valve was dilaterl, and permitted of free regurgitation.

Either of the three agencies already mentioned, operating singly, occasion plainly discernible retadation of the pulse, but when they are combined the delay becomes very narked. An eximple of all three factors, acting together, may be riewed in the tracings exhibited by Fig. 4.

Fig. 4.

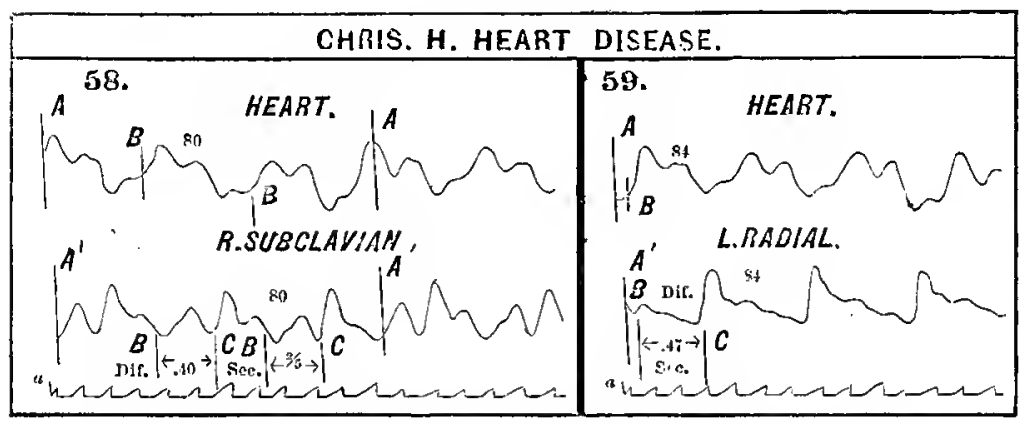

Cardio-subelavian time-difference, $.40=\frac{2}{3}$ sec. Normal the-difference $\frac{1}{1}$ i sec.

The subject from whom these tracings were obtained died November 16, 1879. From the post-mortem notes at the Cincinnati IIospital was glenned the following: Heart fatty, weight 15 ounces; just above the aortic valves were two aneurismal pouches, one projecting forward and to the right, the other forward and to the left. The first contrined no clots, the other was filled witl laminated fibrin, was the size of a small apple, pushed its way in rarious directions, and pressed upon the pulmonary artery in such a manner as to occlude this vessel entirely. The aortic valves were mucl thickened, but competent by the hyclrostatie test. The mitral valve was filled with norlular vegetations and incompetent. Tricuspid and pulmonary valves were normal.

The next cardio-sphygmograms, Fig. 5, instance the pulse delily arising from a combination of heary aortic valves and mitral regurgitation :-

The person supplying tracings Fig. 5 died in the Cincinnati IIospital February 23, 1879. The antopsy showed the aortic valves to be the seat of extraordinary vegetations, not permitting regurgitation, but so heavy as to require material augmentation of the ventricular pressure to 
Fig. 5.

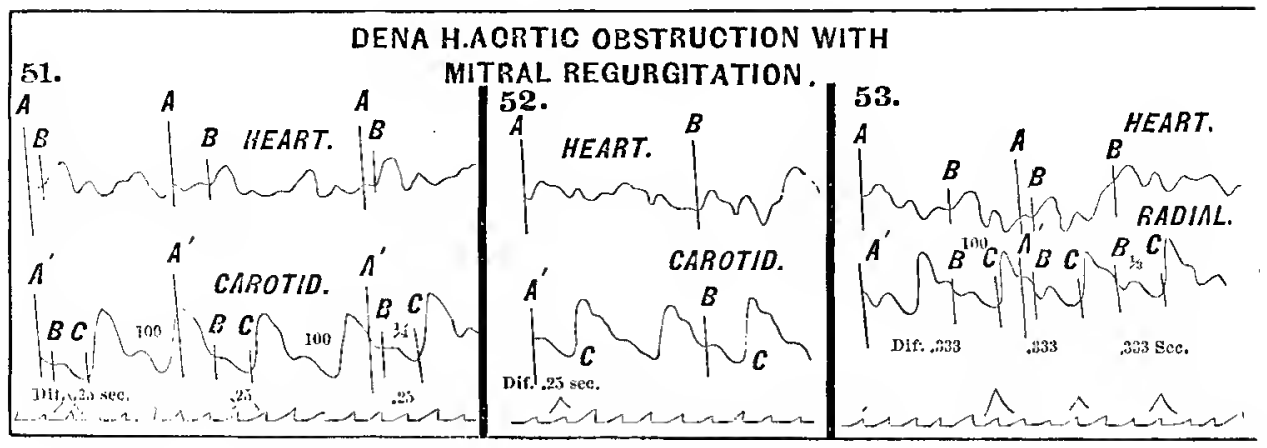

Caldiu-calutid time-differeuce, $.25=\frac{1}{1}$ sec. Normal time-difference ${ }^{1} \frac{1}{2}$ sec.

force them open. The segments of the mitral valve werc thickened, rigid, and manifestly incompetent.

Deciliasing tile Cardo-arterial Time-difference or InterVAI. Aortic Regurgitation.-To M. Franeois Franck ${ }^{1}$ and Dr. Keyt ${ }^{2}$ we owe the knowledige we possess of the influence of aortic insufficiency non the transmission of the arterial pulse wave. By the graphic metlod these investigators lave been enabled to ascertain a decrease in the cardioarterial time-difference as the effeet of aortic regurgitation. Cardiosphygmogiams, Fig. 6, are illustrative.

Fig. 6.

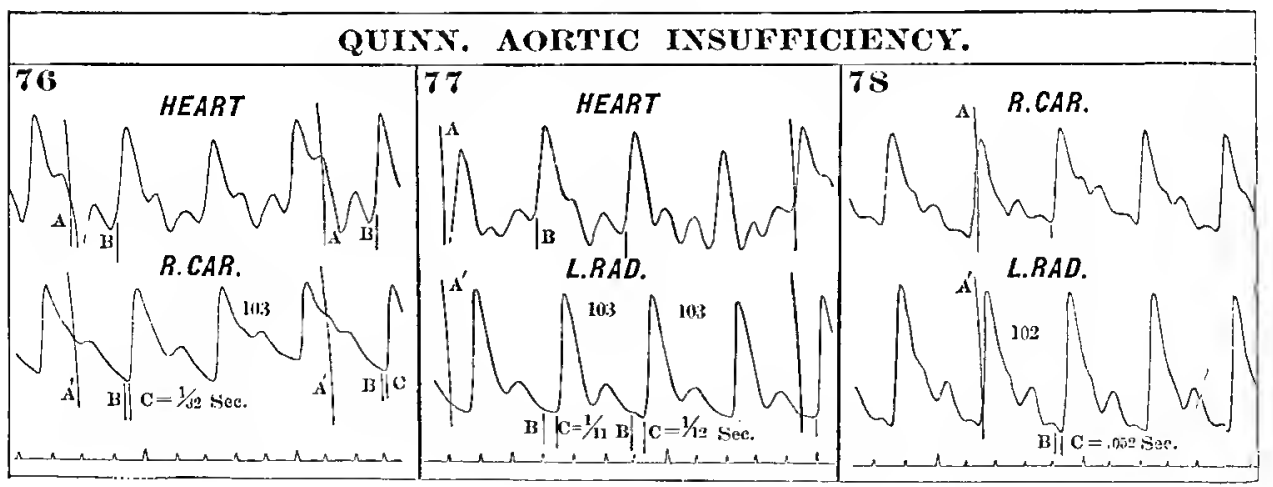

Cardio-carotid timu-difference ${ }_{3}^{1}$ sec. Normal time-difference at $10: 3$ about ${ }_{1}^{1}$ sec.

The case from which were derived the above tracings was in the Cincinnati IIospital, service of Dr. C. G. Comerys. All the usual physical

$$
{ }^{2} \text { Op. eit. } \quad{ }^{2} \text { Op. cit. }
$$


signs of fice aortic regurgitation were present. As yct no opportnnity has been met with to verify pure aroric insufficiency post-mortem. But where the demonstration is so complete that ancurism of sufficient degrec causes pulsc delay, graplic tracings in which this condition figures with aortic regurgitation, become arailable in detcrmining the influence of the latter upon the arterial wave transnissions. Sucl a combination is marked by tracings Fig. 7 :-

Fig. 7 .

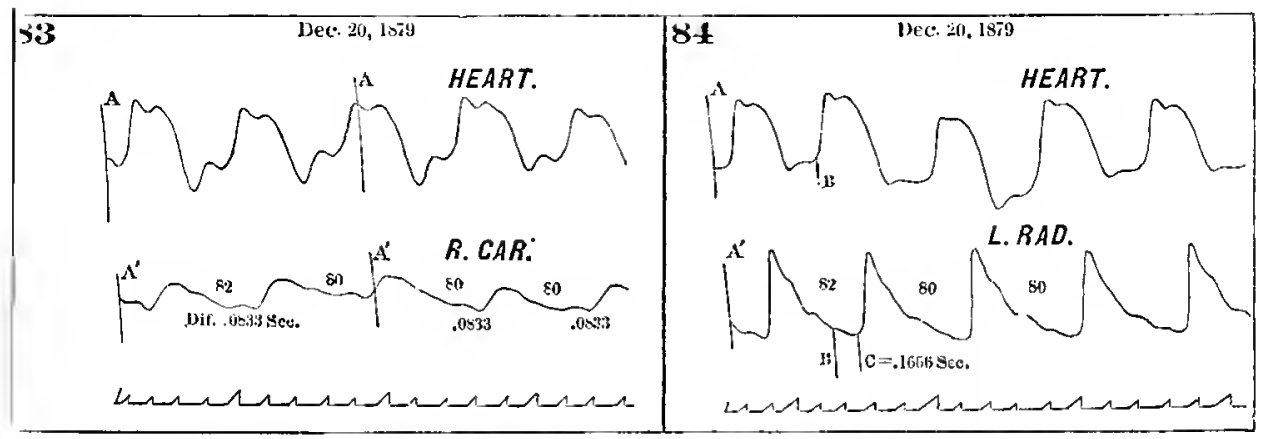

Cardio-carotid timendiference $.05: 33=1 \mathrm{~T}$ sec. Normal time-diference $.0533=\frac{1}{1} \mathrm{z}$ sec.

Tracings Fig. 7 are from a man who had been uncler the professional calre of both Dr. Keyt and.inyself, in whom we found, post-mortem, the left ventricle liypertrophied, the mitral valves sightly thickenerl toward the base, but competent; aortic oritice enlarged and aortic ralves thickened, corrugated, and calcitied througliont, and evidently wholly incompotent. The ascencling aorta was greatly dilated, atheromatous, and studded with calcareous matter, while the transverse portion of the arch was the seat of a large aneurism fully three inches in intcrnal diameter, and with soft and flabby walls.

The aneurism in this case was such as must have causcd notable pulsc delay had it not been counterbalancel by the precipitation of the pulse incident upon aortic regurgitation. 'Tlic precipitation, Dr. Keyt ${ }^{1}$ explains, by presuming that "the base of the arterial column lests against the sides of the ventricle instead of against the aortic valves, and is alranced, causing rise of the pulse with the first movement of ventricular contraction."

Rigid Arteries.-Rigid arterial vessels, such as arc met with in the aged, increase the ratc of pnlse transmission, as may be seen by tracings Fig. 8:-

'Tracings Fig. 8 were from Mrs. B., aet. 78. Slie suffered from dyspnexa, cough, dropsy, and debility, and lad an irrcgular, and, at times, slow pulse. There was a systolic mumur distinct over the cardiac area,

\footnotetext{
'Boston Med. and Surg. Journal, Sept. 30, 1880.
} 
Fig. S.

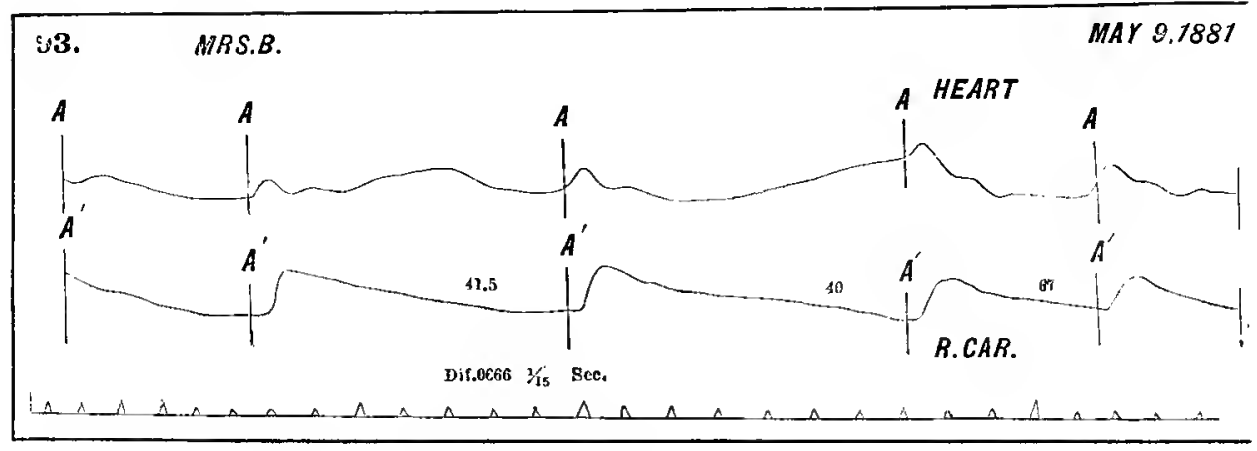

Cardio-carotid time difference about $\frac{1}{15}$ scc. Normal time-diference $\frac{1}{12}$ sec.

plainly heard at both base and apex, but emphasized at a spot midway between these sites. The sccond sound was purc and clear. Tracings were taken at the Cincinnati Hospital May 9, 1881, where she was a private patient under the care of Dr. Keyt. Deatl occmred at Newtown, O., fion dysentery, July 9, 1881, while under the treatment of another plysician. I performed the post-mortem July 11, 1881, in the presence? of Drs. Keyt and Withan and merlical student Jones. The loart was fatty. There were calcareous and falty alterations of arterial walls. The aorta was of normal size, and its orifice was incontracted. The aortic valves were competent, but two segments presented rough calcareous nodules upon their upper aspect. A prominent nodule projected from the ventricular surfice of one segment near its attached border. One segment was fiee fiom calcareous matter, but was slightly expanded and thickened. The valves were perfectly pliable and competent by the hydrostatic test. The mitral and tricuspid valves werc slightly thickencd, but competent, as werc also the pulmonic valves.

In the above case the cardiac second sound was perfectly clear, and there was a systolie murmur with greatest intensity midway between the base and apex. The absence of all indications of aortic regurgitation led to the decision of pulse precipitation from rigid arteries, and the absence of marked evidences of cardiac hypertrophy gave warrant to the conclusion that even in the right heart there could be no material disturbance of valvular action. The precipitation in the case is really much greater than the figures show, since, with a pulse at even 60 per minute, the normal lelay is greatcr than that which we have given for a pulse of 72 per minute. We will have occasion to revert again to these tracings in the eourse of this article.

Having considered the conditions which may affect the rate of pulse transmission, a few words may be devoted to the cardio-sphygmograpline: indications in aortic and mitral stenosis. Aortic stenosis flocs not alter 
the transmission rate of the pulse. A marked degree of stenosis deforms the pulse trace, producing one with sloping ascent and rounded top. It may also occasion intermittency. It all depends, lowever, upon the degree of narrowing. If the orifice is sufficient to permit of pretty free filling of the aorta by the ventricular contraction, the sphymmograplic evidence of aortic stenosis is nil. In regard to mitral stenosis, no cases hare as yet come under observation. From the markings of aortic stenosis, and deductions drawn from the conrse and mechanism of the circulation, it wonld make no variation in the pulsc-rate transmission, but would give rise to a pulse of small tension, and one which might present intermittency at times. The auricular protion of the trace would undoubtedly lave unusual prominence.

Affiections of the valves and orifices of the riglit heart, of course, only have a negative bearing upon cardio-splyygnography, because the blood current which traverses them does not pass into channels accessible for investigation. The nergative value of the spluygmograph in right heart complications is well exhibited by tracings Fig. 9 .

Fig. 9.

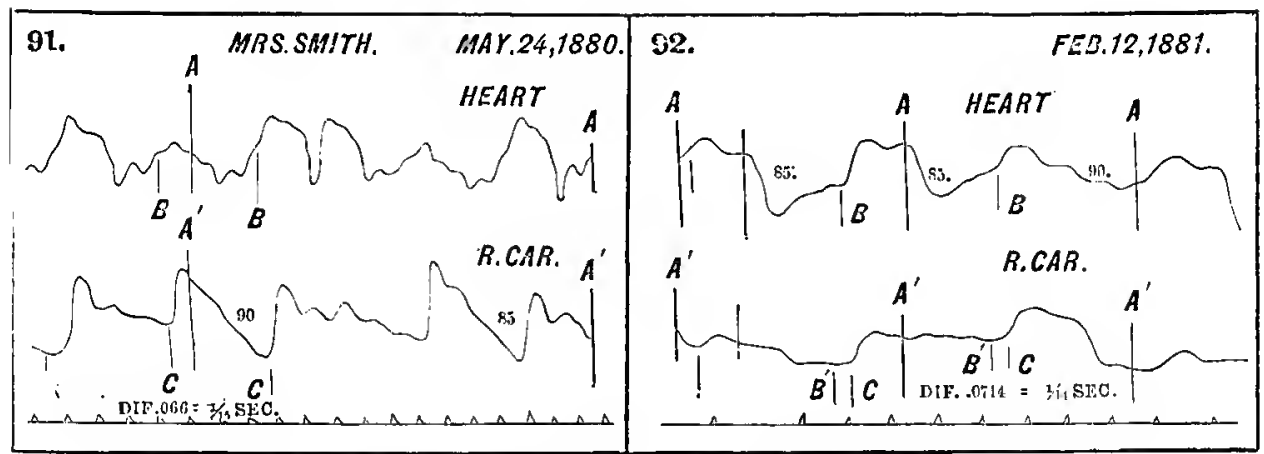

Cardio-carotid time-difference about $\frac{1}{15}$ sec. Normal time-difference with pulse at 9.4 about $\frac{1}{1} \mathrm{~s}$ see.

Tracings (Fig. 9) were from Mrs. Smitl, at. 59. Her symptons werc shortness of breath, inability to exercise, some cough, anasarca of the lower extremities, ascites, and intermittent pulse. 'The area of cardiac dnllness was much increased, showing decided cardiac hypertrophy. There was a loud diffused systolic murmur, plainly accentuated at the apex, and iu all respects, apparently, a typical example of a mitral regurgitant nurmur. The second sound was clear and intensified at the pulmonic site. Traeings were taken in May, 1880, and February 12, 1881. Death occurred May 7, 1881. At the post-mortem, Dr. Keyt being present, we discovered the heart generally enlarged, walls of right auricle and ventricte greatly thickened and the great veins dilated. Pulmonic valves normal; right anriculo-rentricular orifice dilated, and tricuspid valves wholly in- 
competent, one segment being firmly bound down by adhesions to the side of the ventricle. Aortic valves normal; mitral valves slightly thickened, but eompetcit. 'Texture of' lieart fatty and friable.

In the absence of all indications of aortic regurgitation, it was concluded that, in this casc, the left leart was properly functionating, and that the lesion must be located in the right heart, where it would not affect the cardio-artcrial tracings.

The negative eridence the sphygmograph furnishes of perfect valvular mechanism in the left heart finds good illustration in tracings Fig. 8, together with the data and observations thereto pertaining. The negative evidence supplied by the compomm sphygmograph is not less valuable than its positive evidence, and it becomes positive evidence taken in connection with elinical symptoms and plysical and objective signs.

From what hats preceded, though it has been presented rather in the form of an easy lesson in cardio-spliygmograply, it is thought that enough proof has been advanced to establish the graphic methor as an important adjunct in differentiating some of the complex instramentalities which induce disorders in the course of the cireulation, and alterations in normal cardiac aud arterial sounds. Assuming that this much will be almitted, its advantages in life insurance examinations are great.

It is one of the prerequisites to a life insurance policy that the holder shall be a healthy person. Individuals come up fol exanination presum. ably as those who regard themselves perfectly sound, or', at least, presenting no traces of disease detectable to the medical examiner. The examination is male, and an abnormal cardiac murmur is learl. Neither symptoms ol' appeaunce ol anything in the history of the applient show disqualifying lesion,-there is nothing lut this little whilling sound, bearing some relation to the leart beats. Without the graplice methoul the examiner cannot determine whether the sound be structural or functional. Provided the sound be constant, its claracter and location go for nothing in the clifferentiation. The risk cannot be given a clean recommendation. The examiner may say that he belieres the murmur to be functional, and the risk a good one, but lie eamnot state that he has any warrant for this opinion beyond the appearance and history of the applicant, and the probabilities are that if a medical examiner mentions a heart murmur, the medical director will reject the risk no matter low strongly the former expresses his confidence in a sound of functional character. On the other hand, an examiner, by the airl of the graphic mothod, conjoined with other metus of investigation, may base his opinion upon the functional or structural significance of a murmm with almost as much certainty as npon a mathematical demonstration. If the normal pulse delay obtains between the lreart and carotids, and radials and dorsal arteries of the feet, he may say that an instrument of precision gives unequirocal evidence of simplo functional or mechanical origin of the murmur. Isut before he is entitled 
to make so confident an announeement, he must have ascertained that there is no aneurism and aortic regurgitation to eounterlalance each other in their influence upon pulse transmission, and that there are no valvular lesions of the right heart. This he may do by an entirc absence of the clinical symptoms and physical signs indieative of these troublcs. Then, too, if the cardio-sphygmograph reveal abnormal pulse delay or pulse precipitation, or pulse deformation or marked prominence of the anricular portion of the trace, the examiner may say that the instrument of precision, in conneetion with the other features in the case, writes a record of aneurism, or mitral regurgitation, or aortie regurgitation, or aortic or mitral stenosis, as the condition may be. Can an examiner without the assistance of a eompound sphygmograph arrive at a eonclusion with equal certainty? Without exception, where autopsies have been obtained, the conditions of the eirculatory organs bave eorroborated the deductions derived from a study of the eardio-sphyomographie tracing during life.

Every eompetent physician of considerable experienee knows how fallacions many cases of heart murmurs prove themselves. He finds murmurs in some instances in which he is apprehensive of grave cardiac mischief and discovers that they have disappeared, after a time, witlont any apparent harm surviving them. On the contrar, instanees are unfortunately not wanting of supposed innocent murmurs becoming the heralders of serious eardiac discase. It is the uneertainty which even the most accomplished elinician must tieel in regard to many enses presenting eardiae murmurs that makes insurance companies so elsary about aeeepting risks in which there may be possible danger from this source. We think that, with the progress already made in eardio-spliygmography, it is perfectly practicable to distinguish the aeeeptable from the non-aeceptable risks in almost every instance of persons eoming under examination with heart murmurs. This method of investigation is new, its data, as yet, eomparatively limited, but it promises to be developed until nearly every point in cardio-vascular pathology finds its interpretation by this means.

Walivet Hills, Cincixyati, 0 .

Article XII.

A Report of Three Human Monstrosities. By M. A. Koogliz, M.D., of De Graff; Ohio.

OF late the village of De Graff, Ohio, gave record to three monstrosities : one cyclops and two aerania, in less than two months.

'The first occurred in Dr. D. W. Richardson's practice, the second in that of Dr. F. M. Galer's, and the third in the writer's practice.

No. CLXVII._JuLY 1882. 